\title{
Agência e interseccionalidade em quadra: inquietações sobre escolas e diferenças em Mato Grosso do Sul
}

\author{
DUQUE, Tiago ${ }^{1}$ \\ OLIVEIRA, Esmael Alves de \\ BECKER, Simone ${ }^{3}$
}

\section{RESUMO}

As inquietações aqui apresentadas foram suscitadas a partir de duas pesquisas em contextos e temporalidades distintas e que atravessam a trajetória dos autores no Mato Grosso do Sul. A primeira deu-se em decorrência dos diálogos travados por um dos autores com jovens efeminadas (gays, travestis, transexuais) na cidade de Corumbá-MS, na fronteira com a Bolívia. A segunda, foi resultado do diálogo de dois dos autores com jovens indígenas Kaiowá da Terra Indígena (TI) de Panambizinho, localizada a aproximadamente $20 \mathrm{~km}$ de Dourados-MS, no distrito de Panambi. Por meio de uma perspectiva interdisciplinar, sustentada numa análise qualitativa, intenta-se refletir sobre os dilemas e possibilidades que cercam a relação entre minorias e a escola na contemporaneidade a partir de um ponto de vista interseccional. Como resultado, a compreensão de que se a escola continua em vários momentos a se produzir como um espaço de docilização de corpos e subjetividades, de outro, a constante capacidade de negociação e agenciamento dos sujeitos que a enredam.

Escola. Marcadores sociais. Minorias. Agenciamentos.

\section{Agency and intersectionality in court: concerns about schools and differences in Mato Grosso do Sul}

\section{ABSTRACT}

The concerns presented here were raised from two researches in different contexts and temporalities that cross the trajectory of the authors in Mato Grosso do Sul. The first occurred as a result of the dialogues carried out by one of the authors with effeminate young people (gays, transvestites), transsexuals) in the

\footnotetext{
${ }^{1}$ Doutor em Ciências Sociais/Unicamp. Mestre em Sociologia pela Universidade Federal de São Carlos - UFSCar. E-mail: duque.hua@gmail.com. Lattes: http://lattes.cnpq.br/5923842290182625. ORCID: https://orcid.org/0000-0003-1831-0915.

2 Doutor em Antropologia Social/UFSC. Mestre em Antropologia Social - PPGAS/UFAM. E-mail: esmael_oliveira@live.com. Lattes: http://lattes.cnpq.br/5410375038960540. ORCID: https://orcid.org/0000-0002-9235-5938.

${ }^{3}$ Doutora em Antropologia Social/UFSC. Mestre em Antropologia Social pela UFPR. E-mail: simonebk73@gmail.com. Lattes: http://lattes.cnpq.br/8867396183360059.
}

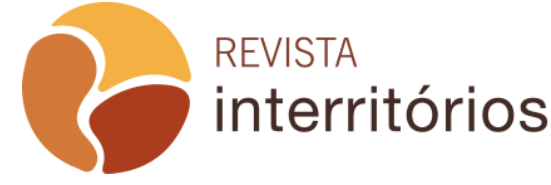

Interritórios | Revista de Educação Universidade Federal de Pernambuco, Caruaru, BRASIL | V.6 N.10 [2020] 
city of Corumbá-MS, on the border with Bolivia. The second was the result of the dialogue between two of the authors with young Kaiowá indigenous people from the Indigenous Land (TI) of Panambizinho, located approximately $20 \mathrm{~km}$ from Dourados-MS, in the Panambi district. Through an interdisciplinary, sustained perspective in a qualitative analysis, we intend to reflect on the dilemmas and possibilities that surround the relationship between minorities and the school in contemporary times from an intersectional point of view. As a result, the understanding that if the school continues at various times to produce itself as a space for the docilization of bodies and subjectivities, on the other, the constant capacity for negotiation and agency of the subjects who enmesh it.

School. Social markers. Minorities. Agency.

\section{Agencia e interseccionalidad en la corte: preocupaciones por las escuelas} y diferencias en Mato Grosso do Sul

\section{RESUMEN}

Las inquietudes presentadas aquí han sido planteadas por dos investigaciones en diferentes contextos y temporalidades que cruzan la trayectoria de los autores en Mato Grosso do Sul, travestis, transexuales) en la ciudad de Corumbá-MS, en la frontera con Bolivia. El segundo fue el resultado del diálogo entre dos autores con el joven indígena Kaiowá de la Tierra Indígena (TI) de Panambizinho, ubicado a unos 20 km de Dourados-MS, en el distrito de Panambi. Mediante una perspectiva interdisciplinaria, respaldada por un análisis cualitativo, pretendemos reflexionar sobre los dilemas y las posibilidades que rodean la relación entre las minorías y la escuela en los tiempos contemporáneos desde un punto de vista interseccional. En consecuencia, el entendimiento de que si la escuela continúa produciéndose en varias ocasiones como un espacio para la docilización de cuerpos y subjetividades, por otro lado, la constante capacidad de negociación y agencia de los sujetos que la involucran.

Escuela. Indicadores sociales. Minorías. Agencia.

\section{Agenzia e intersezionalità in tribunale: preoccupazioni per le scuole e differenze nel Mato Grosso do Sul}

\section{SINTESE}

Le preoccupazioni qui presentate sono state sollevate da due ricerche in contesti e temporalità diversi che attraversano la traiettoria degli autori nel Mato Grosso do Sul. , travestiti, transessuali) nella città di Corumbá-MS, al confine con la Bolivia. II secondo è stato il risultato del dialogo tra due autori con i giovani indigeni Kaiowá della Terra indigena (TI) di Panambizinho, situato a circa $20 \mathrm{~km}$ da Dourados-MS, nel distretto di Panambi. Attraverso una prospettiva interdisciplinare, supportata da un'analisi qualitativa, intendiamo riflettere sui dilemmi e sulle possibilità che circondano la relazione tra le minoranze e la scuola 
nei tempi contemporanei da un punto di vista intersezionale. Di conseguenza, la comprensione che se la scuola continua in varie occasioni a prodursi come spazio per la docilizzazione di corpi e soggettività, dall'altra la costante capacità di negoziazione e di agenzia delle materie che la coinvolgono.

Cuola. Indicatori sociali. Minoranze. Agenzia.

\section{INTRODUÇÃO}

A primeira inquietação aqui apresentada surge da pesquisa realizada por um dos autores junto a jovens efeminadas ${ }^{4}$ (gays, travestis, transexuais) na cidade de Corumbá-MS, na fronteira com a Bolívia, ao longo de 2014 e 2015. O contexto fronteiriço está demarcado por preconceitos, por sua condição de margem. "É um local no qual se pode assimilar a negatividade, atribuída por diversos fatores como o ilícito, a clandestinidade, a miscigenação, entre outros" (OLIVEIRA; CAMPOS, 2012, p. 17). Por isso, parte das atividades que efeminadas desenvolvem na cidade a torna mais valorosa em detrimento do que a realidade fronteiriça está vinculada e em comparação com um "outro" estrangeiro, as apresentações de fanfarras escolares é uma dessas atividades.

A segunda inquietação foi suscitada a partir dos diálogos de dois dos autores com jovens indígenas Kaiowá da Terra Indígena (TI) de Panambizinho, localizada a aproximadamente $20 \mathrm{~km}$ de Dourados-MS, no distrito de Panambi ao longo de 2016. Esse é um dos poucos lugares legitimados pelo papel da lei brasileira como sendo dos indígenas, no estado de Mato Grosso do Sul (ANDRADE e BECKER, 2013), em meio a um contexto onde prevalece a soja e o capital do agronegócio (BECKER, OLIVEIRA, MARTINS, 2016; BECKER, OLIVEIRA, CAMPOS, 2016).

Tanto as efeminadas na região de fronteira demarcada pela negatividade marginal quanto os indígenas no contexto do capital do agronegócio, quando encontrados nas escolas, em especial, nas atividades na quadra das escolas, permitiram-nos discutir a agência desses/as interlocutores/as e pensarmos a produção das diferenças de forma interseccional. Isso porque, do ponto de vista teórico e metodológico, entendemos a diferença como não sendo sempre um marcador de hierarquia e opressão, isto é, necessariamente depreciativo: "é uma questão contextualmente contingente saber se a diferença resulta em desigualdade, exploração e opressão ou em igualitarismo, diversidade e formas democráticas de agência política" (BRAH, 2006, p. 374).

Devido a isso, a escola é entendida aqui como o lugar da espacialização (Rose, 2009). Isto é, ela, a quadra da escola, nos permite tomar o ser humano

${ }^{4}$ Referimo-nos a efeminadas por ser uma categoria que aparece quando é adotada ou auto atribuída por eles/as, ora no masculino, ora no feminino.

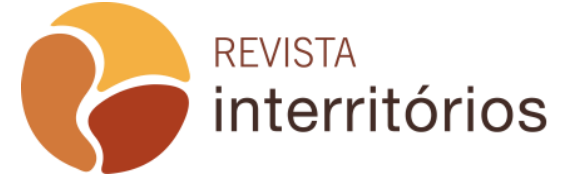

Interritórios | Revista de Educação Universidade Federal de Pernambuco, Caruaru, BRASIL | V.6 N.10 [2020] 
inteligível nos termos de agenciamentos - "a localização e o estabelecimento de conexões entre rotinas, hábitos e técnicas no interior de domínios específicos de ação e valor [...]" (Idem, p.51). As narrativas que seguirão buscarão dar conta disso, de tornar inteligível os processos de agenciamentos que produzem as diferenças em contextos particulares de escolas sul-mato-grossenses.

\section{Da quadra à rua ou quando os aplausos constituem fronteiras}

Em uma noite quente de verão pantaneiro, a quadra de uma das escolas corumbaense estava agitada. A escola, como um todo, estava com as luzes apagadas, tendo apenas uma fraca iluminação em alguns corredores e caminhos que dava acesso a quadra. Não tinha aulas naquela noite, apenas 0 ensaio da fanfarra. Na cidade é muito frequente ocorrer ensaios de fanfarras nas quadras das escolas, que, aproximadamente, somam 30 corporações. Há uma interação bastante frequente de efeminadas nestes espaços pelas funções que eles ocupam: coreografia, elaboração dos adereços de cabeça e brasão das corporações, ensaio das balizas ${ }^{5}$, roupas e maquiagem no dia da apresentação. Estar na fanfarra, ensaiando na quadra e representando a escola nas apresentações públicas (nas ruas, avenidas ou ginásio municipal) não significa necessariamente estar na escola estudando. Algumas não são alunas, outras, abandonaram os estudos ou retomaram depois de mais velhas.

A ausência de uma masculinidade desses interlocutores segundo as expectativas de gênero local, isto é, o fato de eles performarem um certo efeminamento, é compreendido aqui como uma dissidência da matriz de inteligibilidade de gênero apresentada por Butler (2003): "sexo" masculino = gênero masculino = desejo pelo "sexo oposto". Nos casos em questão, há o não cumprimento dessa matriz também em relação ao desejo, isto é, a expectativa de desejo por alguém que não é do "sexo oposto". Por isso eles escapam também a certos controles disciplinares dos prazeres, produzindo uma espécie de sexualidade disparatada (FOUCAULT, 2007). A expectativa da matriz de gênero não correspondida em um primeiro momento, por terem nascido classificadas como do sexo masculino, mas não serem masculinas conforme a norma, como discutiremos, as realocam em posições de efeminamento valorizadas por meio da participação e o envolvimento com as fanfarras escolares.

Podemos compreender que a participação das efeminadas compõem uma gama de atos de gênero, considerando esses atos responsáveis pela ideia de gênero, nos termos de Butler (2003). Afinal, "sem esses atos, não haveria gênero algum, pois não há nenhuma 'essência' que o gênero expresse ou

${ }^{5}$ Pessoas que se apresentam na frente das fanfarras com coreografias, comumente com ações acrobáticas. 
exteriorize [...]" (Idem, p.199). São atos de gênero inteligíveis como femininos. $\mathrm{Na}$ fanfarra escolar, visível desde o ensaio na quadra até as participações públicas, as efeminadas têm lugares bem demarcados, considerando os atos anteriormente citados, mas, inclusive, a própria atuação tocando instrumentos. As efeminadas, em especial, tocam pratos. Não tocam instrumentos de percussão, tidos como mais masculinos. Uma delas me disse: "a cidade toda vai assistir e aplaudir".

Os aplausos são vistos como um ato de reconhecimento, mas também como de diferenciação, afinal, as fanfarras brasileiras compõem um conjunto de eventos que coloca Corumbá (leia-se aqui Brasil) em destaque valorativo, comparado com o "outro" estrangeiro, em especial quando a visibilidade diz respeito a gênero e sexualidade. Isso se dá também em relação a visão que se tem da cidade por brasileiros/as e instituições nacionais de distintas localidades, afinal, Corumbá, mesmo comumente valorizada apelo turismo do Pantanal ${ }^{6}$, por ser fronteiriça, conforme já apontado, é vista negativamente.

Portanto, essas experiências de valorização como as apresentações públicas das fanfarras produzem uma diferenciação da cidade enquanto fronteira, na tentativa de um certo apagamento do estigma de estar a margem e em relação a um "outro" estrangeiro. Frases diferenciadoras da "nossa nação" com a boliviana a partir desses dois marcadores socias (gênero e sexualidade) podem ser "Lá não tem gay", em referência a um lado (outro) menos moderno ou acolhedor, e "Aqui é tudo junto e misturado", como se em Corumbá não houvesse discriminação quando comparado com o país vizinho (DUQUE, 2017). Por isso, a visibilidade das efeminadas nas fanfarras, via os aplausos, por exemplo, e em outros eventos da cidade ${ }^{7}$, diz respeito a um regime de visibilidade ${ }^{8}$ que implica em diferenciações nacionais, constituindo percepções em torno do que entendem como nação.

Octavio lanni definiu nação como estando sempre em movimento, afinada e desafinada, não surge e nem permanece pronta e acabada.

\footnotetext{
${ }^{6}$ Conforme Alexandre Aldo Neves e Cláudio Benito O. Ferraz, entendemos que, atualmente, a ideia de Pantanal "é o resultado de uma diversidade de discursos, enunciado e construções imagéticas que, ao longo da processualidade das relações sócio-econômicas da modernidade ocidental, que nesse lugar se produziu, desdobrou no conjunto de elementos, alguns obscuros e silenciados, outros estereotipados e massificados, que atualmente se interacionam e se tencionam na configuração desse arranjo territorial, o qual se manifesta numa paisagem para além do conjunto natural nele presente" (2012, p. 185).

${ }^{7}$ São eles: desfiles das escolas de samba durante o carnaval, concurso de quadrilhas durante a festa do Banho de São João, Miss Gay, o Musa Gay do Carnaval e o Amistoso da Diversidade.

${ }^{8}$ Entendemos regime de visibilidade como algo que "traduz uma relação de poder sofisticada, pois não se baseia em proibições diretas, antes em formas indiretas, mas altamente eficientes, de gestão do que é visível e aceitável na vida cotidiana" (MISKOLCl, 2017, p.62). Ele envolve uma série de códigos e valores que se impõem como uma espécie de gramática às pessoas envolvidas, nas maneiras como elas podem parecer visíveis (PASSAMANI, 2018).
}

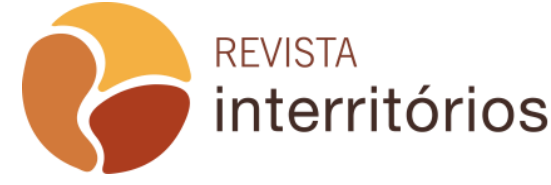

Interritórios | Revista de Educação Universidade Federal de Pernambuco, Caruaru, BRASIL | V.6 N.10 [2020] 
Nasce e renasce, segundo o movimento do seu povo, forças sociais, formas de trabalho e vida, controvérsias e lutas, façanhas e utopias. Resgata ou esquece tradições reais e imaginárias, conforme a fisionomia que se pretende construir no presente, segundo a utopia que vai buscar no futuro. (IANNI, 1988, p. 31).

Assim, mesmo sendo esse caso uma questão de identidades nacionais, generificadas e sexualizadas,

as identidades podem funcionar ao longo de toda a sua história como pontos de identificação e apego apenas por causa de sua capacidade de excluir, para deixar de fora, para transformar o diferente em "exterior", em abjeto (HALL, 2000, p. 110).

Fronteira, então, aqui tem relação com território propriamente dito, mas também com questões identitárias em termos de gênero e sexualidade. Isto é, há fronteiras identitárias de gênero e sexualidade interseccionalizadas com nacionalidade/territorialidade. As fanfarras, como citado anteriormente, contribuem e são produzidas sob essas interseccionalidades.

No que se refere a atuação das efeminadas junto aos instrumentos, dois motivos foram apresentados em campo para que efeminadas tocassem prato e não comumente outros. Mas, todos eles parecem não explicar essa divisão de atos performativos de gênero (BUTLER, 2003). Foi observando o ensaio na quadra que pudemos perceber que os pratos são destinados às efeminadas por algum motivo que não o fato de facilitar mover melhor as mãos durante a coreografia nas apresentações, afinal, outros instrumentos também tornam possível esse ato. Outro motivo apontado que não justifica o fato de elas estarem tocando prato é a ideia de que eles são instrumentos leves, afinal, não são. Então, o que poderia explicar essa restrição performativa em termos de gênero junto a apenas um instrumento diante de uma diversidade significativa que compõe a fanfarra?

Há duas hipóteses para isso, ambas têm relação direta com normas e convenções que estão para além da quadra da escola, ainda que a envolva. A primeira diz respeito a masculinidade viril dos jovens não efeminados, que chegam nas escolas sabendo tocar instrumentos de percussão porque aprenderam nos espaços de religiões de matriz africana. Quem contou isso foi uma das diretoras de uma das escolas da cidade, explicando que é por habilidades que se "escolhe" os instrumentos, e que não necessariamente se aprende a tocar no espaço escolar. É sabido que nos contextos de religiões de matriz africana, mulheres e homens efeminados comumente não tocam 
instrumentos de percussão nos cultos, tendo outras atividades que desempenham. Corumbá é marcado por um enorme número de terreiros de candomblé e umbanda.

A segunda hipótese diz respeito a intencionalidade de efeminadas serem identificadas como femininas, mas com um feminino valorizado, inclusive, por ser mais feminino do que as próprias mulheres, afinal, as mulheres tocam pratos e alguns outros instrumentos, mas, principalmente prato. Durante os ensaios, o prato é o lugar mais feminino da quadra em termos de "atos de gênero". Depois, somente a posição de baliza que ganha destaque como sendo "de mulheres". Mas, ainda assim, algumas efeminadas apresaram-se como baliza/balizador, agradando muito o público, conforme pode ser observado em apresentações oficiais, mas essas tendem a ser mais jovens e mais magras, por isso, tocar prato favorece um maior número de efeminadas.

Assim, compreender a quadra das escolas, durante os ensaios, como um importante espaço de agenciamento (ROSE, 2009), que favorecerá o sucesso das apresentações públicas das fanfarras, nos faz compreender sob quais normas e convenções as efeminadas estão agindo. Os custos dessas negociações garantem o reconhecimento enquanto femininas, seja por não tocar instrumentos de percussão típicos dos terreiros de religiões afro-brasileiras, lidos nesses locais como atividade masculina, seja por ser melhor do que as próprias mulheres tocando prato ou se apresentando como baliza, segundo o olhar crítico de várias pessoas da cidade, inclusive mulheres. Essas experiências corroboram o quanto o reconhecimento é algo que se dá necessariamente por um caminho comum entre histórias singulares, e esse caminho o coloca em circulação (BUTLER, 2007). Isso porque "o reconhecimento é uma relação intersubjetiva, e, para um indivíduo reconhecer o outro, ele tem que recorrer a campos existentes de inteligibilidade" (BUTLER, 2010, p. 168)

Esses campos de inteligibilidade passam pela escola, mas não necessariamente transforma o contexto escolar no que se refere às normas binárias de gênero. Afinal, segundo um instrutor de fanfarra, as direções das escolas normalmente aceitam efeminadas com certo limite, especialmente na comissão de frente, que é o lugar mais valorizado da fanfarra (os/as jovens levam o brasão da escola e as bandeiras - município, estado e país). Segundo ele: "As pessoas julgam: 'ah, só travesti. Aquela banda lá, só travesti'”. E, diante desse julgamento, ele avalia: "Acho que nenhum diretor de colégio gostaria de ser conhecido como uma escola assim: 'Ah, aqui a comissão de frente é só de travestis, só gays na comissão de frente"”. Mas, também destaca: "o diretor sempre quer uma banda ou fanfarra do colégio para divulgar o colégio".

Contudo, segundo os estudos de Fernandes (2019), as fanfarras, devido ao fato de mostrar as qualidades das jovens em coreografar, maquiar, produzir adereços e figurinos, permite que elas, via essas atividades, adquiram um 
emprego, por exemplo, nas escolas de samba como aderecistas, coreógrafas ou figurinistas, ou em outras atividades que envolve essas habilidades. Há relatos também de efeminadas que começaram a trabalhar com dança depois da experiência da fanfarra, que permite uma espécie de aprendizado profissional.

\section{Da escola à quadra ou quando "correr" é o único modo de falar}

Nossas interações com os jovens da escola indígena Pa'i Chiquito, localizada na terra indígena (TI) de Panambizinho-MS, foram disparadas com um projeto de extensão coordenado por uma das autoras. Desde o primeiro dia de trabalho de campo conjunto, uma das inquietações suscitada foi: em que medida a estrutura da escola, apesar de se localizar dentro de uma comunidade indígena e ter como perspectiva pedagógica uma prática "intercultural", pouco se coadunava com o contexto de onde estava inserida e, consequentemente, é pouco sensível às especificidades do público atendido - crianças e jovens indígenas. ${ }^{9}$ Nesse sentido, para nós foi emblemático tanto a dimensão estrutural e relacional da escola (p. e. a organização da sala de aula e das formas de relação estabelecidas entre professores/as e alunos/as), quanto algumas mensagens fixadas na sala da administração e que dava a entender trata-se de um ambiente altamente disciplinador.

Com relação à tais mensagens haviam muitas com conteúdo enunciando interdições: "não se pode usar o computador da secretaria para trabalhos pessoais", "não se pode colocar os capacetes de motocicletas em cima dos assentos existentes na secretaria", "não se pode isso", "não se pode aquilo"...Muitos "nãos", muitos "não pode".

Spivak (2010) ao refletir sobre os mecanismos que produzem a subalternização, nos provoca com uma pergunta desestabilizadora: "Pode o subalterno falar?" Para a autora indiana, o direito a fala tem sido histórica e colonialmente monopolizado impossibilitando que vozes periféricas e subalternas falem. Mas seria a possibilidade de fala suficiente para o acesso a essa autonomia? Em cena outro paradoxo: e se falassem? Seriam escutados? Num contexto do "não pode", "não faça", "não é permitido", de uma permanente interdição, negação do outro, não há espaço para a existência, ou pelo menos não a existência autônoma. Não se daria aí a emergência de regime de verdade que busca produzir um sujeito sem palavras? ${ }^{10} \mathrm{E}$ qual tem sido historicamente

\footnotetext{
${ }^{9}$ Tomamos aqui tais categorias como produções social e historicamente marcadas e datadas (ARIĖS, 1981). Importa dizer que no contexto das sociedades indígenas infância [e juventude] são atravessadas por processos relacionais que não se esgotam numa compreensão de desenvolvimento biopsíquica (COHN, 2005).

${ }^{10}$ Vale a pena mencionar a instigante fala de Joziléia Jagso Inácio Jacodsen em duas mesasredondas na semana de antropologia da UFPR, ocorrida em setembro de 2016. Ao tocar na questão da permanência e ingresso dos indígenas nas pós-graduações stricto sensu Brasil,
}

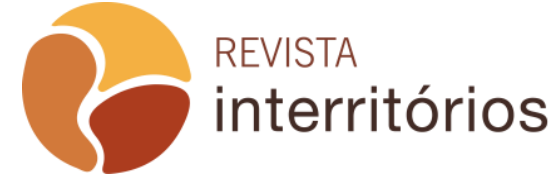


- papel da escola dentro da produção desses processos de subjetivação "afônicos"?

Durante o trabalho de campo, ocorreram duas situações que consideramos paradigmáticas: uma delas referente a uma fala feita pelas crianças indígenas durante uma atividade de desenho que realizávamos e outra diretamente relacionada ao comportamento dos mesmos durante o intervalo para o lanche - sob os disparos indeléveis da sineta do "recreio" (onde foi possível observar como eles operam uma forma lúdica de circular - correndo e muito - pelo espaço de fora da escola/quadra de futebol).

Em relação à primeira situação, logo que começamos o trabalho, em um clima bem descontraído, as crianças e jovens estavam bem à vontade com nossa presença. As crianças brincavam o tempo inteiro e, nesse aspecto, é possível observar que a jocosidade como um elemento constantemente presente do processo de interação. Tal comportamento não está livre de tensionamentos, principalmente com relação aos professores não indígenas, que em vários momentos externalizavam suas dificuldades pessoais em dialogarem com aquele contexto. Isso se manifestava, sobretudo, nos momentos em que se exigia as crianças e jovens mantivessem uma "postura adequada à sala de aula" e também no processo pedagógico quanto às estratégias para tornar o conteúdo programático assimilável pelos estudantes indígenas. ${ }^{11}$

Certamente uma transposição de um modelo que se não impede de todo a fala, a engessa, a normatiza e, por que não dizer, a medicaliza à medida que normaliza. Em relação a esse ponto, alguns comentários chamaram muito nossa atenção: quando os indígenas eram interpelados pela professora a se "comportarem" e prestarem atenção no que estávamos falando, eles, em tom de "brincadeira" começaram a acusar uns aos outros de não ter tomado o medicamento. Isso não passou despercebido por nós. Naquele mesmo momento tentamos instigá-los a falar mais e, no entanto, não entraram em mais detalhes.

$\mathrm{Na}$ semana seguinte durante outra atividade, voltaram a mencionar a tal falta de "tomar o comprimido". Nessa nova oportunidade nos deparamos com a seguinte resposta: "os agitados tomam o comprimido". À nossa pergunta "E o

ainda não afora, ela mencionou o quanto o aparelho do Estado brasileiro é perverso. Isto porque exigiu do índio ao longo do processo de integração - ou genocídio escancarado como projeto político - apre(e)nder e manejar o idioma português e não falando sua língua nativa. $A$ antropologia explorará o quanto falar de etnicidade é falar de linguagem (CUNHA, 2009), e então das fronteiras sempre fluidas entre o "eu" e o "outro" que nas sociedades indígenas em regra se dá condicionado à relação. Mas mais do que isto, o quanto quem detém o poder pode re-produzir vida mais precária (BUTLER, 2003) ainda a partir da negação de uso da linguagem falada, como no caso dos indígenas. Afinal como nos acalenta Walter Benjamin, não há produção do humano se não há (re)produção de memória (1987).

${ }_{11}$ Por exemplo, em determinado momento do trabalho de campo, uma das professoras compartilhava conosco suas dificuldades em trabalhar conteúdos específicos que, segundo ela, contrastavam com a lógica local.

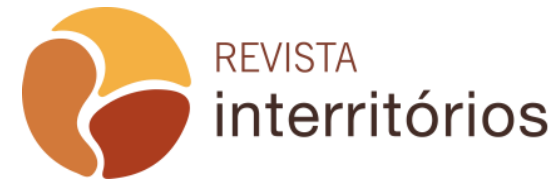

Interritórios | Revista de Educação Universidade Federal de Pernambuco, Caruaru, BRASIL | V.6 N.10 [2020] 
que são os 'agitados'?", a resposta: "aqueles que não se comportam direito como os professores pedem para se comportar". E continua: "Quem dá muito trabalho na escola, os pais vão no postinho e o médico receita o comprimido, aí fica calminho, calminho". Em cena, uma forma perversa de um regime de saberpoder que se auto-completa: de um lado a escola com seu regime normalizador de produção de corpos e "almas" dóceis/educados, de outro a medicina (e o campo psi) com seus sistemas nosológicos de produção do "anormal" (MILAN, 2019).

Cabe lembrar que há muitos relatos de medicalização dos indígenas na cidade de Dourados - embora até o momento não haja nenhuma pesquisa a esse respeito - e que geralmente são associados a algumas situações de violência ou aos casos de suicídio. Em todos eles, a noção de que os indígenas precisam ser contidos, estão desequilibrados, doentes, etc. Em todas essas representações uma noção de patologização do sujeito que está à margem, com vidas precarizadas pelo Estado e que transbordam pelas suas formas e estilos de vida dissidentes as contenções das estruturas estatais. Esse cenário acima narrado, nos ajuda a pensar em que medida há um contexto de medicalização do corpo, do sujeito (MILAN, 2019; OLIVEIRA, MARTINS, 2020). Medicalização essa entendida no sentido amplo. Pensada a partir da perspectiva foucaultiana, poderíamos até dizer que há uma tentativa de docilização dos corpos constituída a partir de um aparato biopolítico (FOUCAULT, 2007). Saber-poder, que opera endógena e exogenamente, ou seja, no interior dos corpos e consciências, por meio da medicalização em si, mas também nos comportamentos e subjetividades, através de um aparato institucionalizante (escola, hospital/posto de saúde, etc.).

No que concerne à segunda situação, era como se fosse possível observar um pequeno corte: se na primeira cena, crianças e jovens com "dificuldades de se comportar" ("indisciplinadas"), na segunda, diante do toque a sineta a emergência de um corpo que corre e que se ressignifica a partir do lúdico. Foi assim que, ao soar o sinal para o intervalo, as crianças e jovens indígenas saíram em disparada para pátio e em seguida para a quadra. No pátio, se mantiveram apenas até o momento em que comiam o lanche que era distribuído para eles. Comendo muito apressadamente, o ato seguinte foi o de sair rapidamente para a quadra. Ali, era como se a criançada fosse outra. Ou seja, nada se comparava ao comportamento reprimido, as vezes meio apático, visto em sala de aula. Ao contrário, um imenso contraste entre uma vida que pulsa (fora) e uma "morte" que tenta se estabelecer nos corpos docilizados pelo sistema de ensino (dentro) tradicional.

Num primeiro momento poderíamos ser tentados a uma leitura fatalista da primeira cena e uma compreensão ufanista da segunda. Contudo, para nós estava claro que em ambos os cenários, tanto no que se refere à sala de aula quanto a experimentação em torno da

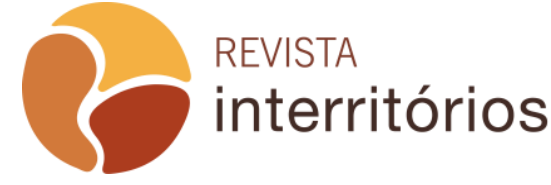


quadra, eram constituídos e atravessados por resistências e re-existências que se operam no interior do sistema. Desse modo, não era atoa a admoestação quanto ao comportamento. Assim, as brincadeiras jocosas, a fala em guarani, a corrida para fora do espaço escolar durante o recreio, o adormecer em meio às falações enfadonhas dos professores durante as aulas, eram modos possíveis de situar-se e produzir-se no campo da contestação.

Essa contestação nem sempre se produz a partir de rupturas claras e explícitas. Ao contrário, também faz-se por silêncios, por imagens (era comum observarmos a elaboração de pequenos grafismos no caderno nos momentos em que a aula estava acontecendo), por gestos, enfim, por colocar nas relações estabelecidas a expressão de nossas posições de sujeitos no mundo e ao fazêla "modestamente" instaura um espaço de instabilidade questionadora. Não por acaso, algumas de nossas tantas experiências prenhes de significados se deu quando em roda estávamos em meio à contação de histórias. Numa delas, um dos jovens nos alertou que as histórias ${ }^{12}$ sobre o lobisomem - (identificado por eles com o cunhado), eram lendas e não histórias [grifo nosso]. Afinal, era assim que a professora tinha "ensinado". Num contexto que tende a constituir corpos docilizados (como o da escola tradicional) a produção de uma narrativa que reitera sua própria visão de mundo e que passa a nomear o que era interdito [considerado meramente como da ordem do mito] remete a um agenciamento de um sujeito que não se contenta com a posição de assujeitado, mas que assume para si a função de narrador (BENJAMIN, 1986). Em cena formas sutis de resistência.

Vale lembrar que educar vem do latim educare, por sua vez ligado a educere, verbo composto do prefixo ex (fora) + ducere (conduzir, levar), significando 'conduzir para fora', ou seja, preparar o indivíduo para o mundo. Um indivíduo relacional, produzido na unicidade da troca entre dois diferentes, correspondendo à fórmula n-1 deleuze-guattariana. $\mathrm{O}$ que seria essa fórmula?

\begin{abstract}
O livro como imagem do mundo é de toda maneira uma ideia insípida. Na verdade, não basta dizer Viva o múltiplo, grito de resto difícil de emitir. Nenhuma habilidade tipográfica, lexical ou mesmo sintática será suficiente para fazê-lo ouvir. É preciso fazer o múltiplo não acrescentando sempre uma dimensão superior, mas, ao contrário, da maneira mais simples, com força de sobriedade, no nível das dimensões de que se dispõe, sempre n-1 (é somente assim que o uno faz parte do múltiplo, estando sempre subtraído dele). Subtrair o único da multiplicidade a ser constituída: escrever a n-1(DELEUZE e GUATARRI, 1995, p. 14-15).
\end{abstract}

${ }^{12}$ Ao utilizarmos a consoante $\mathrm{h}$ para nos referirmos a uma narração que seria comumente entendida como fabulação (portanto, "estória"), desejamos marcar uma posição epistemológica de questionamento ao modelo eurocentrado que tem historicamente se sustentado e justificado a partir de pares de oposição assimétricas (tais como história/ "verdade" e estória/mito).

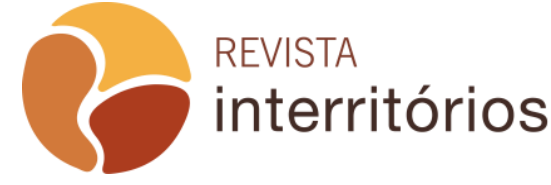


Ao mesmo tempo importa ressaltar que a palavra saber está associada etimologicamente com sabor. Ou seja, ambas incorporam origens de sentidos similares. Segundo o "Dicionário Etimológico da Língua Portuguesa" de José Pedro Machado (1967), a palavra saber vem do latim 'sapere', que significa "ter gosto; exalar um cheiro, um odor; perceber pelo sentido do gosto; fig., ter inteligência, juízo; conhecer alguma coisa, conhecer, compreender, saber". A palavra sabor, segundo o mesmo dicionário, deriva do latim 'sapore-', que quer dizer "gosto, o sabor característico de uma coisa, em sentidos próprios e figurado; no pl., coisas de bom gosto; odor, perfume; gosto, acção de provar; (...)."

Não seria esse o sentido impresso pelos os jovens indígenas da escola Pa'i Chiquito? Por meio de suas experimentações e "corridas" subvertem o modelo domesticador de corpos e dilacerador de sabores nos saberes em que prevalece o panóptico escolar. Subversão que se dá com eles não escondendo quando dormem, dispersam, riem, sorriem...

Assim, como um oposto simétrico da escola, a quadra imprime uma outra experiência do aprender e do experimentar o que é ser criança e jovem indígena Guarani Kaiowá. Ali enredasse uma dinâmica outra de resgatar o sabor do saber. Naquele lugar precário, sem cobertura, exposto ao calor intenso do sol, a vida vivida daquelas crianças e jovens indígenas constitui-se como possibilidade de expressão e interação menos atrelada à cadência da constância da disciplina escolar.

Milan (2019), em sua dissertação de mestrado, aponta para os mecanismos necropolíticos que se produzem em torno de determinadas vidas [no geral vidas precárias]. Ao realizar sua pesquisa junto a uma escola pública localizada na cidade de Dourados e que fica próxima de um condomínio popular [onde reside a maioria dos estudantes], o autor problematiza como a escola tem sido tornado um instrumento de captura de subjetividades. Num contexto de medicalização da vida, há uma série de proliferação de laudos.

Esse é apenas um lado da moeda, o outro, uma escola que tem dificuldades para lidar com a realidade social de seu alunado e que (quando não bastam os laudos) acaba por investir numa arquitetura que em nada difere de uma instituição prisional (com o predomínio de muitas grades). Por meio de sua pesquisa somos conduzidos a perceber que o racismo de estado (FOUCAULT, 2010), está envolto em complexas teias sócio-histórico-econômico-culturais concretas e que encontram nos marcadores sociais (classe, raça/etnia, região, religião, geração etc.) a sustentação para a produção de sua maquínica de guerra. Algumas vezes em práticas sutis, difusas, outras vezes deliberadamente em práticas violentas, declaradas, concentradas.

Estes textos não são como um oráculo que nos fala de nosso próprio futuro mutilado. Vêm nos recordar que o que estamos vivendo não é um 
processo natural, mas uma fase a mais de uma guerra que não cessou: a mesma guerra que levou à capitalização das áreas de preservação indígena, ao confinamento e ao extermínio de todos os corpos cujos modos de conhecimento ou afecção desafiavam a ordem disciplinar, à destruição dos saberes populares em benefício da capitalização científica, à caça às bruxas, à de corpos humanos para serem convertidos em máquinas vivas de plantação colonial (PRECIADO, 2018, p.11).

Mas como dissemos anteriormente, esse é apenas um lado da moeda. $E$ talvez se perdêssemos de vista a capacidade de agenciamento dos sujeitos que historicamente experimentam esses contextos de violência e docilização, estaríamos a operar na mesma chave daquilo que buscamos criticar/combater. Ao contrário, o que encontramos em nosso trabalho de campo, e o trabalho de Milan também endossa, é como apesar de toda esta maquínica de governo da vida os sujeitos resistem, re(existem). Assim, pensar numa perspectiva interseccional implica não perder de vista as porosidades, os vasos comunicantes, os jogos de espelhos que fazem com que essas fronteiras sejam relativizadas e que nos oportunizem pensar as ambiguidades, as mímeses, os sentidos e imaginários compartilhados. Afinal,

quando parece que "tá tudo dominado", como dizia o funk, no extremo da linha se insinua uma reviravolta que ressignifica a própria dominação como segunda. Aquilo que parecia submetido, subsumido, controlado, dominado, isto é, a vida, revela num processo mesmo de expropriação a sua positividade indomável e primeira. Não se trata de romantizar uma capacidade de revide e de resistência, mas sim de repensar a relação entre os poderes e a vitalidade social na chave da imanência. Poderíamos resumir esse movimento do seguinte modo: ao poder sobre a vida, biopoder, responde a potência da vida, biopotência. Ao biopoder responde a biopotência, ao poder sobre a vida responde a potência da vida (PELBART, 2015, p. 21).

Sobre o (re)tornar interseccionalmente à quadra - à guisa de (in)conclusão

Nos termos de Ortner (2007), a agência tem a ver com a intencionalidade e com o fato de se perseguir projetos, sempre culturalmente definidos. E, também, de forma entrelaçada, com o poder, com o fato de agir em contextos de relações de desigualdade, de assimetria e de forças sociais. Isso implica dois aspectos: por um lado, mesmo que os indígenas e as efeminadas pareçam, como outros/as pessoas, que, no final das contas, a partir das experiências em quadra, estejam agindo conforme a sua própria vontade e querer, a agência deve ser lida sempre como algo para além de quem age, constituída e constitutiva de 
um externo que independe do seu "querer". Por outro, e ao mesmo tempo, essa aparente "predeterminação" dada pelo contexto, antes de significar cooptação ou impossibilidade de "movimentar-se", aponta para a constante necessidade de negociação criativa dos sujeitos e coletivos na produção de (micro)resistências.

Nas duas situações de pesquisa, não podemos perder de vista que se a escola se constitui em vários momentos como dispositivo disciplina, é a partir dela, e em seu entorno, que tanto indígenas quanto efeminadas são capazes de produzir formas alternativas de se produzirem como sujeitos ativos de seus processos de subjetivação. Dessa forma, o que a experiência de estudantes indígenas e efeminados nos alerta é que os processos de mobilização, negociação e resistência são dinâmicos e sempre inconclusos. Se na sala/escola é difícil ser quem se é, há sempre a possibilidade criativa de produzir-se em outros espaços. E por que não na(s) quadra(s)?

E o que tudo isso implica numa abordagem interseccional? A perspectiva da interseccionalidade, como aponta Piscitelli (2008), às vezes recebe críticas por parte de muitas pessoas por dar pouca ênfase à experiência e mais atenção aos eixos classificatórios (CRENSHAW, 2002), como os de raça, gênero, sexualidade, etnia, geração etc. Aqui, chamamos a atenção para as nossas reflexões diante das inquietações que tivemos em torno das experiências de indígenas e efeminadas em quadra, entendo-os/as não como um "sujeito da experiência", já plenamente acabado e constituído a quem as "experiências acontecem", ao invés disso, reconhecemos que a experiência é o lugar da formação do sujeito (BRAH, 2006).

A experiência, portanto, é entendida aqui como "o que nos passa, o que nos acontece, o que nos toca. Não o que se passa, não o que acontece, ou o que toca. A cada dia se passam muitas coisas, porém, ao mesmo tempo, quase nada nos acontece" (BONDIA, 2002, p. 20). Dito de outro modo, não se trata de negar opressões referentes a existência dos eixos classificatórios, antes, reconhecer que eles não necessariamente "tocam", a todo o momento, a todos/as da mesma forma. Eles, mesmo "acontecendo", não necessariamente "nos acontece"; mesmo quando eles nos "tocam", ou porque eles nos "tocam", temos espaços para a (re)ação, ainda que, às vezes, correspondendo a processos normativos e convencionados. $O$ que sim é que essa convencionalização não torna-se impedimento para o agir, para o movimentarse, para o (re)ssignificar (BUTLER, 2017). ${ }^{13}$

\footnotetext{
${ }^{13}$ Para pensar a agência como zona de possibilidade criativa, inspiramo-nos na ambivalência proposta por Butler. Conforme a autora, não podemos ignorar que o poder tanto subordina quanto produz: "Se Foucault argumentou que um signo pode ser absorvido e usado para fins contrários àqueles para os quais foi projetado, é porque entendeu que até os termos mais nocivos poderiam ser apropriados, que as interpelações mais prejudiciais também poderiam ser o lugar da reocupação e da ressignificação radicais" (Butler, 2017, p. 112).

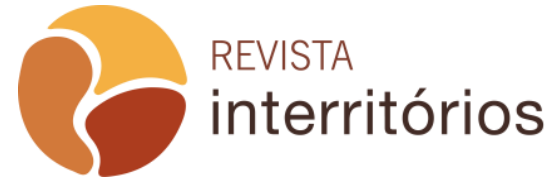


A capacidade de agência constituída e constitutiva das experiências em campo dos interlocutores aqui apresentados não é apenas deles/as. Essas inquietações transformadas em reflexão não deixaram de ser a nossa própria experiência interseccional em campo. Se perceber em processos de intersecção, com uma determinada agência, parece ser um ponto importante para o campo da Educação, pois nos direcionará a reflexão, e, ao mesmo tempo nos permitirá complexificar $o$ olhar diante da realidade interseccionada das e pelas experiências que desejarmos estudar.

Assim, (re)tornar interseccionalmente à escola se constitui num movimento epistêmico importante à medida que se reconhece a impossibilidade de que sujeitos e experiências sejam devidamente compreendidos sem os atravessamentos que os produzem histórica e socialmente. Não entendemos tal desafio como uma impossibilidade. Antes constitui-se como característica fundamental de uma escola que esteja engajada com os enfrentamentos aos dispositivos de exclusão e estigmatização. Em nossa perspectiva, o que nosso trabalho de campo junto a efeminadas e indígenas permitem inferir é que, se há a permanência de uma série de processos de opressão e subalternização (eixos classificatórios), não podemos perder de vista que sujeitos e coletivos têm historicamente dado mostras de dinâmicas estratégias individuais e coletivas (agências), seja na sala de aula, seja na quadra, de enfrentamentos de relações sociais não igualitárias e assimétricas. Mas estamos dispostos/as a aprender interseccionalmente com as experiências deles/as?

\section{REFERÊNCIAS}

ANDRADE, Rogério de; BECKER, Simone. E a chaminé? Relatos etnográficos sobre políticas públicas e a terra indígena (TI) de Panambizinho. Espaço Ameríndio (UFRGS), v. 7, p. 172-204, 2013.

BECKER, Simone; OLIVEIRA, Esmael Alves de; CAMPOS, Marcelo da Silveira. "Onde fala a bala, cala a fala". Disponível em: http://brasildebate.com.br/guaranikaiowa-onde-fala-a-bala-cala-a-fala/. Acesso em: jul. 2016.

BECKER, Simone; OLIVEIRA, Esmael Alves de; MARTINS, Cátia Paranhos. "Onde fala a bala, cala a fala": resistências às políticas da bancada da bala, do Boi e da Bíblia em MS. Disponível em: http://encenasaudemental.net/post-destaque/onde-falaa-bala-cala-a-fala-resistencias-as-politicas-da-bancada-da-bala-do-boi-e-da-biblia-emms/. Acesso em: jul. 2016.

BENJAMIN, Walter. Experiência e pobreza. In: BENJAMIN, Walter. Obras escolhidas, volume 1. São Paulo: Editora Brasiliense, 1987.

BENJAMIN, Walter. O narrador. In: BENJAMIN, Walter. Magia e Técnica, arte e política: ensaios sobre literatura e história da cultura. 2. ed. v. 1. São Paulo: Brasiliense, 1986. 
BONDIA, Jorge Larrosa. Notas sobre a experiência e o saber de experiência. Revista Brasileira de Educação, Rio de Janeiro, n. 19, p. 20-28, abr. 2002. Disponível em: <http://www.scielo.br/pdf/rbedu/n19/n19a02.pdf>. Acesso em: 25 fev. 2020.

BRAH, Avtar. Diferença, diversidade, diferenciação. Cadernos Pagu, 26, p. 329-376, 2006. Disponível em: <http://www.scielo.br/pdf/cpa/n26/30396.pdf>. Acesso em: 25 fev. 2020.

BUTLER, Judith. A vida psíquica do poder: Teorias da sujeição. Belo Horizonte: Autêntica, 2017.

BUTLER, Judith. Conversando sobre psicanálise: entrevista com Judith Butler. Entrevista concedida a Patrícia Porchat Pereira da Silva Kunudsen. Revista Estudos Feministas, Florianópolis, v.18, n.1, p. 161-170, 2010. Disponível em: <http://www.scielo.br/pdf/ref/v18n1/v18n1a09.pdf>. Acesso em: 25 fev. 2020.

BUTLER, Judith. Condição humana contra "natureza". Diálogo com Adriana Cavarero. Revista Estudos Feministas. vol.15, n.3, p. 650-662, 2007. Disponível em: <http://www.scielo.br/pdf/ref/v15n3/a09v15n3.pdf>. Acesso em: 25 fev. 2020.

BUTLER, Judith. Problemas de Gênero: Feminismo e Subversão da Identidade. Rio de Janeiro: Civilização Brasileira, 2003.

COHN, Clarice. Antropologia da criança. Rio de Janeiro: Zahar, 2005.

CRENSHAW, Kimberlé. Documento para o encontro de especialistas em aspectos da discriminação racial relativos ao gênero, Estudos feministas, 1, p.171-189, 2002. Disponível em: < http://www.scielo.br/pdf/ref/v10n1/11636.pdf>. Acesso em: 26 fev. 2020.

CUNHA, Manuela Carneiro da. Cultura com aspas. São Paulo: Cosac\& Naify, 2009. DELEUZE, Gilles; GUATARRI, Félix. Mil platôs: Capitalismo e esquizofrenia. V. I. São Paulo: Ed. 34, 1995.

DUQUE, T. "Lá não tem gay": fronteira e relações de vizinhança envolvendo gêneros dissidentes e sexualidades disparatadas em Corumbá (MS). MNEME, v. 18, p. 111124, 2017. Disponível em: <https://periodicos.ufrn.br/mneme/article/view/12275/9335>. Acesso em: 25 fev. 2020.

FERNANDES, Sanderson Fardim. As trajetórias de "jovens trans" na fronteira Brasil/Bolívia: (in)visibilidade nas escolas públicas de Corumbá (MS). Dissertação (Mestrado em Educação) - Universidade Federal de Mato Grosso do Sul, 2018.

FOUCAULT, Michel. História da sexualidade: A vontade de saber. Rio de Janeiro, Edições Graal, 2007.

FOUCAULT, Michel. Aula de 17 de março. In: FOUCAULT, Michel. Em defesa da sociedade. São Paulo: Martins Fontes, 2010.

HALL, Stuart. Quem precisa de identidade? In: SILVA, Tomaz Tadeu (org.) Identidade e diferença - a perspectiva dos estudos culturais. Petrópolis: Vozes, 2000. p. 103133. 
MACHADO, José Pedro. Dicionário etimológico da língua portuguesa. s/l: Editorial Confluência, 1967.

MILAN, Ezequias Freire. Dos “professores de verdade" às "crianças laudadas" do "condomínio que ninguém entra": Etnografia em espaços reprodutores de práticas necropolíticas e de (re)existência em Dourados/MS. Dissertação (Mestrado em ANTROPOLOGIA) - Universidade Federal da Grande Dourados, 2019.

MISKOLCI, Richard. Desejos digitais: uma análise sociológica da busca por parceiros on-line. Belo Horizonte: Autêntica Editora, 2017.

NEVES, Alexandre Aldo; FERRAZ, Claudio Benito O. Cinema no Pantanal: construindo uma paisagem a partir das imagens. In: MORETTI, Edvaldo Cesar; BANDUCCI JUNIOR, Alvaro. (Orgs). Pantanal: territorialidades, culturas e diversidade. Campo Grande, MS: Ed. UFMS, 2012. p. 173-199.

OCTAVIO, Ianni. A questão nacional na América Latina. Estudos Avançados, vol. 2, n 2, São Paulo, p. 5-40, 1988. Disponível em:

<http://www.scielo.br/pdf/ea/v2n1/v2n1a03.pdf>. Acesso em: 25 fev. 2020.

OLIVEIRA, Marco Aurélio Machado de; CAMPOS, Davi Lopes. Migrantes e fronteira: lógicas subversivas, vidas referidas. In: PEREIRA, Jacira Helena do Valle; OLIVEIRA, Marco Aurélio Machado de (orgs.). Migração e integração: resultados de pesquisa em Mato Grosso do Sul. Dourados: Editora UFGD, 2012. p. 17-37.

OLIVEIRA, Esmael Alves de; MARTINS, Catia Paranhos. Sobre Práticas de Medicalização e "Loucura": Algumas Reflexões In(disciplinadas). Revista Psicologia e Saúde, v. 12, p. 101-113, 2020.

ORTNER, Sherry. Poder e Projetos: reflexões sobre a agência. GROSSI, Miriam et al. (Org.). Conferências e Diálogos: saberes e práticas antropológicas. Brasília: ABA/ Nova Letra, 2007. p. 45-80.

PASSAMANI, Guilherme Rodrigues. Batalha de Confete: envelhecimento, condutas homossexuais e regime de visibilidade no Pantanal-MS. Rio de Janeiro: Papéis Selvagens, 2018.

PELBART, Peter Pal. Políticas da vida, produção do comum e a vida em jogo... Saúde Soc. São Paulo, v.24, supl.1, p.19-26, 2015.

PISCITELLI, Adriana. Interseccionalidades, categorias de articulação e experiências de migrantes brasileiras. Sociedade e Cultura. vol.11, n. 2, p. 263-274, 2008. Disponível em: <https://www.revistas.ufg.br/fchf/article/view/5247/4295>. Acesso em: 25 fev. 2020.

PRECIADO, Paul. La isquierda bajo la piel: um prólogo para Suely Rolnik. In: ROLNIK, Suely. Esferas da insurreição: Notas para uma vida não cafetinada. São Paulo: n1 Edições, 2018.

ROSE, Nikolas. A governamentalidade e a história da escola moderna: outras conexões investigativas. Educação \& Realidade, n. 34, v. 2, p 97-117. 2009. Disponível em: <https://seer.ufrgs.br/educacaoerealidade/article/viewFile/8434/5542>. Acesso em: 25 fev. 2020. 
SPIVAK, Gayatri Chakravorty. Pode o subalterno falar? Belo Horizonte: Editora UFMG, 2010. 